\title{
Non-invasive system and procedures for the characterization of liquid-liquid dispersions
}

\author{
M.M.M. Ribeiro ${ }^{\text {a }}$, M.M.L. Guimarães ${ }^{\text {a }}$, C.M.N. Madureira ${ }^{\text {b }}$, J.J.C. Cruz Pinto ${ }^{\text {c, } *}$ \\ a Dep. Engenharia Química, Instituto Superior de Engenharia do Porto, Oporto, Portugal \\ ${ }^{\mathrm{b}}$ Faculdade de Engenharia, Universidade do Porto, Oporto, Portugal \\ ${ }^{\mathrm{c}}$ CICECO/Dep. Química, Universidade de Aveiro, Aveiro, Portugal
}

Received 31 January 2003; accepted 9 June 2003

\begin{abstract}
A novel dispersed phase imaging system for batch/continuous agitated vessels is described in detail, together with the relevant drop-size distribution and data treatment procedures. This system enabled the non-invasive study of toluene-in-water agitated liquid-liquid dispersions. Most of other similar studies are invasive of the system's structure and behavior, which raises questions about the quality of the generated data. Drop-size distributions have been collected and used for testing the representativeness and stability of the samples obtained, and positively assess the physical meaningfulness of the results through the effects of the main operating variables-mean residence time, agitation intensity and dispersed phase hold-up. Inter-drop coalescence clearly shows its effects even in very lean agitated dispersions, and thus cannot be neglected; its modeling, however, is still very much an open question as will be shown in another paper.
\end{abstract}

(C) 2003 Elsevier B.V. All rights reserved.

Keywords: Non-invasive dispersed phase imaging system; Drop-size distribution

\section{Introduction}

Knowledge of dispersed phase size distributions in liquidliquid and other multiphase processing equipment is required as a basis for the design and optimization of the hydrodynamic, mass transfer [1] and chemical reaction [2-4] performance of the system. Non-first order fluid-fluid reacting systems are particularly sensitive to the dispersed phase size distribution and interaction dynamics. The sensitivity of mass transfer efficiency calculation to drop-size distribution was recognized many years ago by Olney [5] and more recently by Korchinsky et al. [6,7] and Rod and Misek [8]. These authors demonstrated, by both calculation and experiment, that serious design and performance prediction errors occur if drop-size distribution is neglected.

Although experimental techniques are often difficult and tedious to implement, drop size has been the most widely studied aspect of liquid-liquid mixing in agitated vessels and an attractive research area, considering the relative success of the theory and modeling of drop behavior, even for complex phenomena such as coalescence-redispersion [9-13].

\footnotetext{
* Corresponding author.

E-mail address: cpinto@dq.ua.pt (J.J.C. Cruz Pinto).
}

During the last few decades, several drop-size measurement techniques have been developed or adapted from solid particle size measurements. Bae and Tavlarides [14] discussed the operating range and limits of applicability of the then available techniques in terms of dispersedphase fraction $\left(\phi_{\mathrm{d}}\right)$ and drop-size resolution, although time resolution - an important item in strongly agitated dispersions-was not considered. Most of these techniques were employed to measure the drop-size distribution (or the mean drop size) in lean dispersions $\left(\phi_{\mathrm{d}}<5 \%\right)$, either under steady-state conditions or in transients following step changes in the agitator speed. The variety of currently used techniques somewhat reflects the complexity of the experimental problems to be overcome [15].

Other very valuable and advanced experimental techniques, such as electrical resistance or capacitance tomography [16,17], while providing significant structural and operational information, lack the detail-discriminating power needed in physically realistic and accurate quantitative descriptions and modeling of liquid-liquid systems.

According to Pacek et al. [18], any technique based on representative physical sampling will drastically change the overall composition of the dispersion, unless recycling is used. If recycling were to be used, it would still modify the process under study, especially the local composition at 


\begin{tabular}{|ll|}
\hline \multicolumn{2}{|c|}{ Nomenclature } \\
$d_{32}$ & Sauter-mean diameter \\
$D$ & impeller diameter \\
$L$ & vessel height \\
$n$ & degrees of freedom \\
$N$ & impeller speed \\
$T$ & vessel diameter \\
& \\
Greek letters \\
$\theta$ & mean residence time \\
$\phi$ or $\phi_{\mathrm{d}}$ & dispersed phase volume fraction \\
\hline
\end{tabular}

the point(s) where the sample is taken and returned to the vessel. Additionally, physical sampling of dispersions with a wide drop-size distribution either would require large sampling times (unsuitable for rapid transients) or the representativeness of the sample would be questionable. Bae and Tavlarides [14] discussed the influence of the capillary diameter on the accuracy of drop-size measurements and have shown that accuracy requirements practically exclude all methods that involve physical sampling, including the capillary technique, whichever method is used to convert the length of the stretched drops into size of equivalent spheres. Other recent work [19] has lead to the same conclusion.

One of the earliest and the most common direct method for the acquisition of drop-size distributions is conventional (analog) photography. This is a simple, easy and accurate method, but it cannot be used for high hold-up fractions, especially in the case of optically dark dispersion systems, and usually requires a large number of pictures and lengthy analysis time. Direct image analysis of the data has thus met with limited success for dilute dispersions of large drops.

The only other direct techniques involve digital photography. With a standard photo camera, the need for frequently repeated images is still a major problem. However, by replacing the standard camera by a video camera, this limitation can be successfully overcome, as Pacek et al. [18] have done. As remarked by Pacek and Niewnow [20], video techniques will allow: (i) rapidly repeated data collection; (ii) accurate drop measurement from a few tens of microns to a few millimeters; (iii) continuous monitoring even for very long periods, as may be required when a physically relevant event occurs at a time difficult to predict; (iv) high hold-up tolerance (if internal probe and lighting is used); (v) semi-automatic data treatment, i.e., significantly more rapid than that possible with conventional photography.

A particularly important aspect of the video technique is that, because of the high framing rate of the camera, enough drops to compute the drop size average and distribution (traditionally about 800 have been thought as being required) can be measured in a short time. Full size distributions are also required for understanding coalescence-driven tran- sients, since coalescence rates are strongly size-dependent [21].

Disadvantages of the video technique are first that it is feasible only if good pictures can be obtained, i.e., the system must be transparent and the two phases must be of greatly different refractive index. Second, although data treatment may be made much more efficient than for analog photography, it is still very tedious, contrasting with the longestablished capillary technique, which handles this issue very smoothly. In order to fulfil the requirements set out for measuring drop-size distributions in a mixing vessel, the video technique must be complemented with a microscope and suitable lighting. Work with video systems equipped with purpose-built endoscopes of adequate magnification and shallow field-depth seems promising.

In the present work, which is just a first step in a broader research program, we tested this technique with nonintrusive probes, i.e., tried to obtain high quality pictures of a small region inside a transparent vessel near its wall, lighting and observing it from the outside.

This paper describes in full detail this novel non-invasive experimental batch/continuous agitated vessel and dispersed phase imaging system, together with the relevant procedures for data treatment.

For large vessels, the distance from the wall at which pictures can presently be obtained may not be sufficient to meet vessel-sampling requirements, while invasive methods do not have this limitation. Later, if necessary, we intend to test the selected video equipment with intrusive probes, i.e., using optical fiber probes for suitable lighting and/or endoscope video micrography.

\section{Experimental}

\subsection{Mixer-settler pilot plant}

The liquid-liquid system under study was toluene (dispersed)-water (continuous), which is one of the systems recommended by Misek [22]. The physical properties of this system are listed in Table 1.

Different mixer geometries and types of agitator paddles are used both in laboratory and industrial work; however, in hydrodynamic studies [23-27] six plane paddle turbines and cylindrical vessels with height $=$ diameter are most common. Such a geometrical standardization is useful in order to allow comparison between different studies.

In this study, a $T=L$ (diameter = height), 6.281 vessel with flat bottom, equipped with four flat vertical baffles, was

Table 1

Physical properties of the toluene-water system at $25^{\circ} \mathrm{C}$

\begin{tabular}{llll}
\hline Liquid & $\begin{array}{l}\text { Density } \\
\left(\mathrm{kg} / \mathrm{m}^{3}\right)\end{array}$ & $\begin{array}{l}\text { Viscosity } \\
(\mathrm{mPa} \mathrm{s})\end{array}$ & $\begin{array}{l}\text { Interfacial } \\
\text { tension }(\mathrm{mN} / \mathrm{m})\end{array}$ \\
\hline Toluene & 862 & 0.552 & 32 \\
Water & 997 & 0.8903 & 32 \\
\hline
\end{tabular}




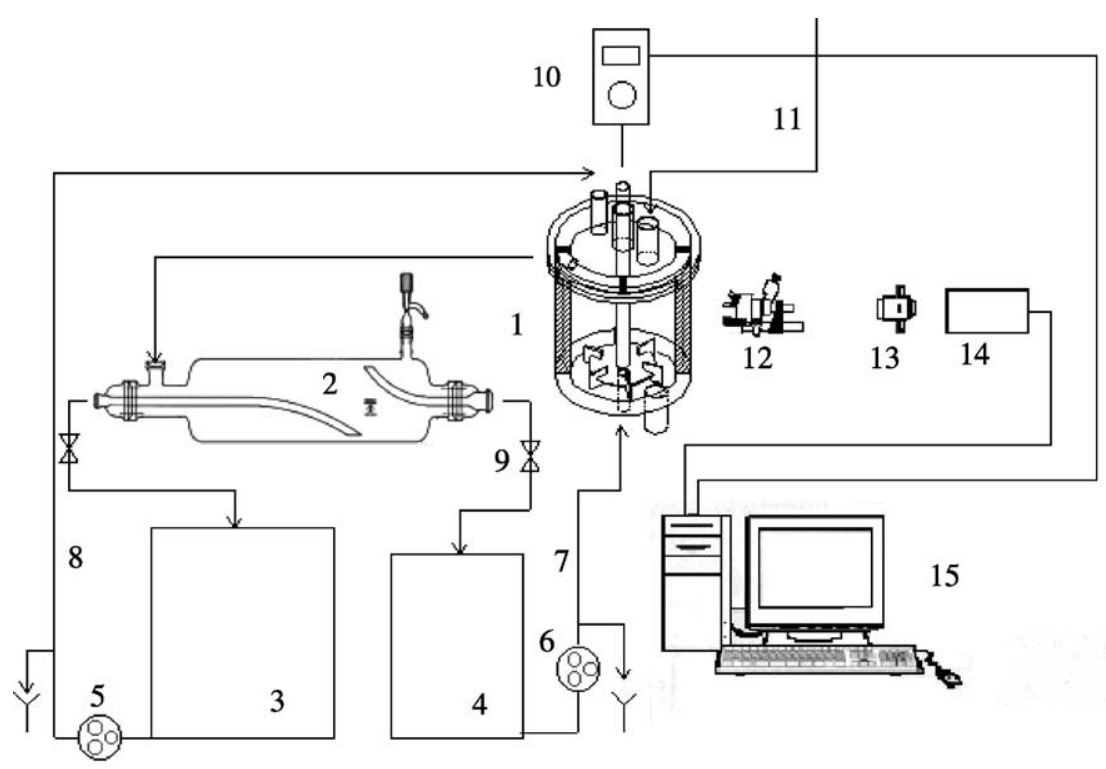

\section{Legend:}

1- mixer; 2 - settler; 3,4 - tanks; 5, 6 - peristaltic pumps; 7, 8 - tubing; 9 - valves; 10 - agitator; 11 - air entrance; 12 - microscope; 13 - adapter; 14 - video camera; 15 - computer.

Fig. 1. Schematic drawing of the mixer-settler equipment and apparatus for data acquisition.

used. In current studies, the most common ratios between turbine and vessel diameters $(D / T)$ are $1 / 2$ or $1 / 3$. In the present work, a Rushton turbine with a 1/2 turbine/vessel ratio and a turbine diameter/disk diameter/paddle width/paddle height of 20/15/5/4 was used [23,24].

The experimental set-up is shown in Fig. 1, with a mixer-settler arrangement working in closed circuit, the mixer feeds being forced in by peristaltic pumps. Both pumps and pipes were selected for an average residence time of the mixture in the mixer between 1 and $10 \mathrm{~min}$, with dispersed phase hold-ups between 1 and $10 \%$.

\subsection{Non-invasive image acquisition technique}

\subsubsection{Equipment selection, assembling and tuning}

In order to develop the new image acquisition technique, several trial tests and experiments were performed, their sequence depending on the demonstration equipment types available in the market. Table 2 shows the different types of video camera and lighting system thoroughly tested (cf.
PRAXIS XXI/EQU/13190/1998 project report [28], for thorough details). The black-and-white SensiCam camera, designed for weak lighting and fast movement (exposure times from $1 \mathrm{~ms}$ to $1000 \mathrm{~s}$, image intervals between 0 and $1000 \mathrm{~s}$ ), has at last been judged adequate for our purpose.

Mechanical assembly of the whole acquisition and lighting outfit required a robust, low-cost and use-flexible design. Particularly, the microscope-camera group required a rigid support structure on a heavy camera tripod, allowing for independent positioning, with efficient vibration damping.

Despite the high sensitivity of the camera, the lighting system had to respond to strict requirements of targetability, no-flicker, high light density, low heat generation and simple and safe set-up. In this regard, several conjectures (e.g., high frequency and three-phase fluorescence, immersed point sources, electronic, flat and halogen lamps), were made and a few were actually tested. Of these, only the latter showed promise, so that normal halogen lamps (up to $500 \mathrm{~W}, 220 \mathrm{~V}$ ) and integral, cool, concentrated sources $\left(150 \mathrm{~W}, 12 \mathrm{~V}, 7^{\circ}\right)$ were seriously tested. The solution adopted for our studies

Table 2

Types of video camera and lighting system tested

\begin{tabular}{|c|c|c|}
\hline Video camera & Lighting & Result \\
\hline Sony DXC120 P & Nikkon $6468 \mathrm{UN}+$ overhead projector & Preliminary test \\
\hline Canon with macro objective lens and adapter & Halogen $500 \mathrm{~W}$ & No images obtained \\
\hline Canon with normal objective lens & Halogen $500 \mathrm{~W}$ & Insufficient amplification \\
\hline Sony DXC95OP & Halogen $500 \mathrm{~W}$ & Duplicated images \\
\hline SensiCam long exposure CCD cooled & Halogen $500 \mathrm{~W}$ & Good quality images \\
\hline
\end{tabular}


(A)

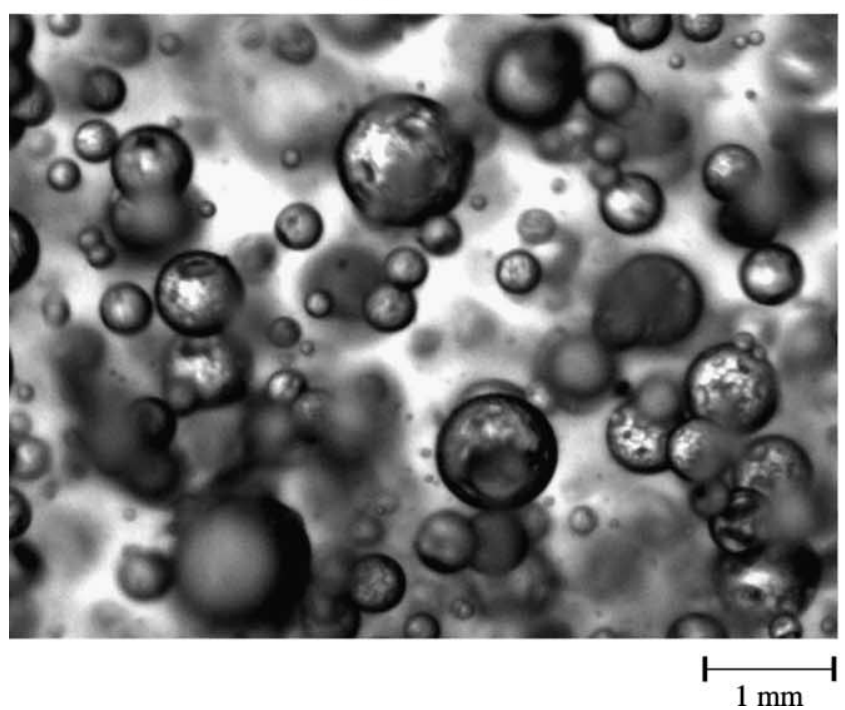

(B)

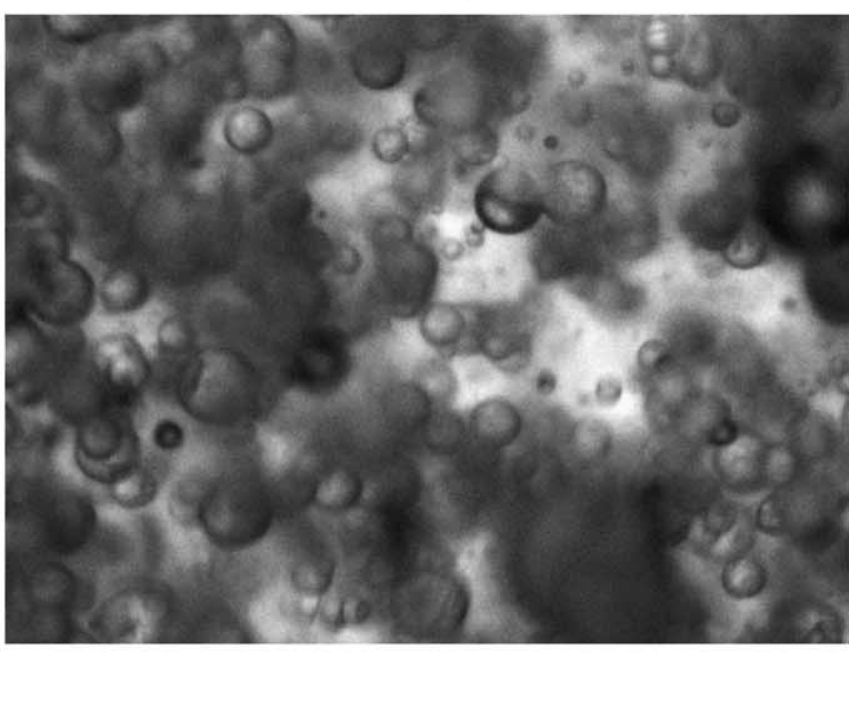

Fig. 2. Typical images: (A) very good pattern image (12 drops measured); (B) difficult pattern image (4 drops measured).

was made up of four cool halogen lamps $(150 \mathrm{~W}, 12 \mathrm{~V}$ each), with mirror-concentrated beam and rear cooling. However, to considerably improve the quality of lighting and significantly increase the maximum accessible dispersed phase hold-up fraction, focusing lighting systems (laser and other forms of collimated beams) are now also being considered. As shown below, this first set-up proved adequate to accurately reveal physically important features of the behaviour of liquid-liquid dispersions, namely the importance of inter-drop coalescence, even in very lean dispersions, in addition to the usual, better known, effects of the main process operating variables. Test trials enabled the definition of the best placement of the microscope-camera group, the best arrangement of the lighting array and the penetration depth (up to $3 \mathrm{~cm}$ ) into the vessel.

For each experimental set-up, the amplification of the combined optical-imaging system was determined from images of a gauge made from calibrated wire immersed in the vessel.

Minimum frame duration (1 ms) was used in routine work, so that drop images show no trails even at the highest agitation speeds. In this way, many frames (up to 1000) may be obtained per second, which enables the selection, in each frame, of only the best-defined drops without representative sample size problems.

Long drop trails generated by long frame durations were used in order to estimate the apparent velocity of drops under different agitation speeds, and so to compute the minimum time interval between frames for which consecutive images do not contain the same drops, i.e., consecutive samples are independent (for safety reasons, $1 \mathrm{~s}$ time interval between images was adopted as standard in routine work).

Depending on the agitation rate, dispersed phase hold-up and mean residence time, the image frames showed different degrees of measurement difficulty, as shown in Fig. 2A and $\mathrm{B}$, which were acquired in a continuous system with $1.85 \%$ dispersed phase hold-up, $167 \mathrm{~s}$ average residence time and 110 and $142 \mathrm{rpm}$ agitation speeds, respectively.

\subsubsection{Image treatment and analysis}

After acquisition, the images must be treated in order to extract the drop-size distribution of the sample. From exploratory work, a preliminary treatment to enhance drop contour contrast and annihilate large amounts of image noise was shown to be mandatory. In fact, shadows of out-of-focus drops are equivalent to noise, and refraction haloes around drop image contours generate poor image definition.

Three different software packages for image treatment were tested: Microimage 3-Olympus, a demonstration copy provided by LABCONTROLE, Optimas, a trial version offered by INFAIMON, and Scion Image for Windows, freely available from the Internet (http://rsb.imfo.nih.gov). Since the two former ones seemed to offer no significant advantage, the latter was chosen for routine use.

On the pre-treated computer images, drop sizes were measured by means of a custom-written routine developed within the Scion Image environment. Under this routine, the mouse is used to define three points on the perimeter of one visually identified drop; the software then automatically draws the corresponding circle over the photo-image. Thus, if the operator has misplaced one point (which would lead to a wrong size determination) he can visually detect the mistake and repeat the point selection. After all well defined drops have been measured in enough frames to provide a representative sample, an ASCII (.txt) file is exported to a $\mathrm{Mi}$ crosoft Excel spreadsheet, where a macro (i) converts drop size from pixels to centimeters, (ii) drop volumes are automatically classified into 50 different logarithmic size classes, 
from $10^{-7}$ to $10^{-2} \mathrm{~cm}^{3}$ and (iii) the contents of each class is finally counted and the results expressed as number and volume fractions.

Ongoing work now concentrates on fully automating the entire drop size data collection and treatment along the following lines: after adequate image pre-treatment, horizontal and vertical scanning of drop border yield pixel triplets, from which preliminary size and location estimates are computed. Usually there are many different estimates for each drop resulting from ill-defined contours, as well as mistaken identifications (ghosts) resulting from border pixels coming from different drops. This latter effect is minimized by frame decomposition into contiguous sub-frames in which only proportionate diameters are considered. These estimates are then stochastically filtered in three-dimensional (abscissa, ordinate, diameter) space as relevant local modes, in order to produce unambiguous drop identification and "ghost" rejection (cf. PRAXIS XXI/EQU/13190/1998 project report [28]).

\subsection{Experimental procedure and validation of the technique}

Although the continuous flow mode is the one which offers greater industrial interest, experiments were carried out under both batch and continuous conditions, in order to compare and explore their results.

\subsubsection{Representativeness}

Another step in the preliminary test program was the acquisition of information about the number of measured drops necessary in order to give statistically significant estimates of the drop-size distribution. This was performed by comparing estimates of the average drop volume obtained from samples of different sizes. For this study, a typical experimental run was selected under continuous flow conditions, with $\theta=167 \mathrm{~s}, N=113 \mathrm{rpm}$ and $\phi=1.85 \%$, for which 4270 different drops were measured from 482 different frames (thus, on average, less than nine drops were identified and measured in each frame by this semi-automated procedure).

Average of logarithm of drop volume series data in Fig. 3 show that, under the chosen experimental conditions, a minimum sample size of about 1000 drops seems necessary. However, another way of looking at the problem is illustrated in the same figure, where the standard deviation of the average of logarithm of drop volume is shown as a function of the number of drops in the sample, alongside its moving 200-drop average. Analysis of this plot shows that a more reliable estimate of the minimum number of drops in a representative sample is about 1500 . For greater safety, the standard sample size for routine work was defined as 2000 drops.

\subsubsection{Study of the reproducibility/stability of the results}

The first pre-requisite for a reproducibility study is for the system to have effectively attained its stationary state. From the point of view of system dynamics, the (perfect) mixing process is a first order system, so that the response to a step input reaches $95 \%$ of its final level in thrice the average residence time in the system. Since a real stirred vessel always deviates more or less from perfect mixing, we used 10 times this estimate (a value which Bapat [29] also adopted) as a minimum for the steady-state regime to be established, in order to have a proper safety margin.

A series of six runs was performed, sequentially designated by $\mathrm{A}-\mathrm{F}$ (113 rpm agitation rate, $1.85 \%$ dispersed phase hold-up and $167 \mathrm{~s}$ average residence time), in order to study the reproducibility of the experimental results of this work. In each run, two series of frames were obtained $3 \mathrm{~h}$ (almost 65 times the residence time; frames $3 \mathrm{hA}$ to $3 \mathrm{hF}$ ) and $5 \mathrm{~h}$ after start-up (frames $5 \mathrm{hA}$ to $5 \mathrm{hF}$ ); for run $\mathrm{F}$ a further series of frames was obtained after an intermediate $4 \mathrm{~h}$ (series $4 \mathrm{hF}$ ). The aim for the different frame series (corresponding to different time delays) was to test the effective stabilization of each run.

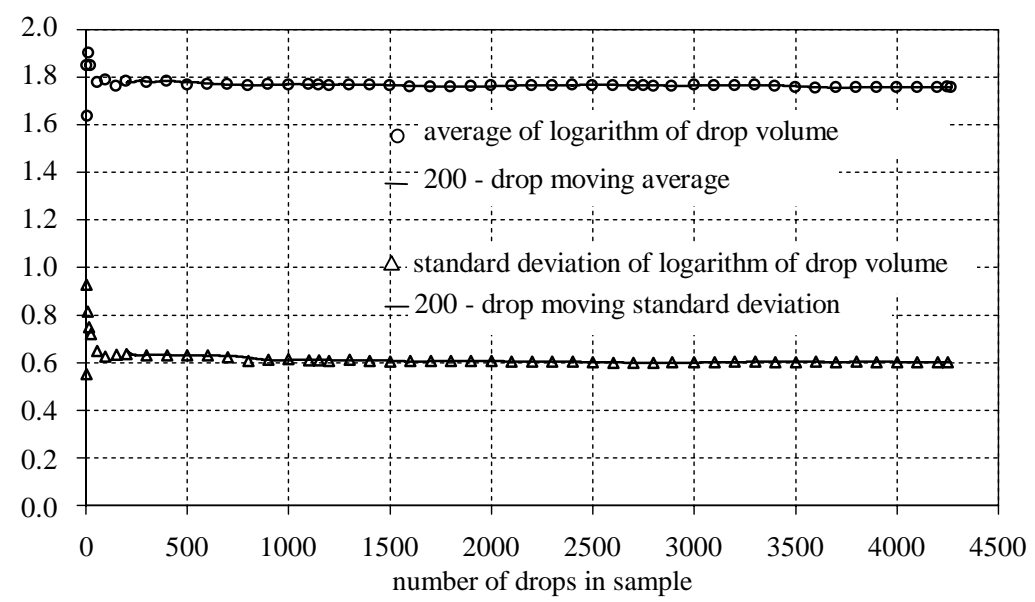

Fig. 3. Average of logarithm of drop volume estimates and standard deviation of logarithm of drop volume as a function of sample size. 


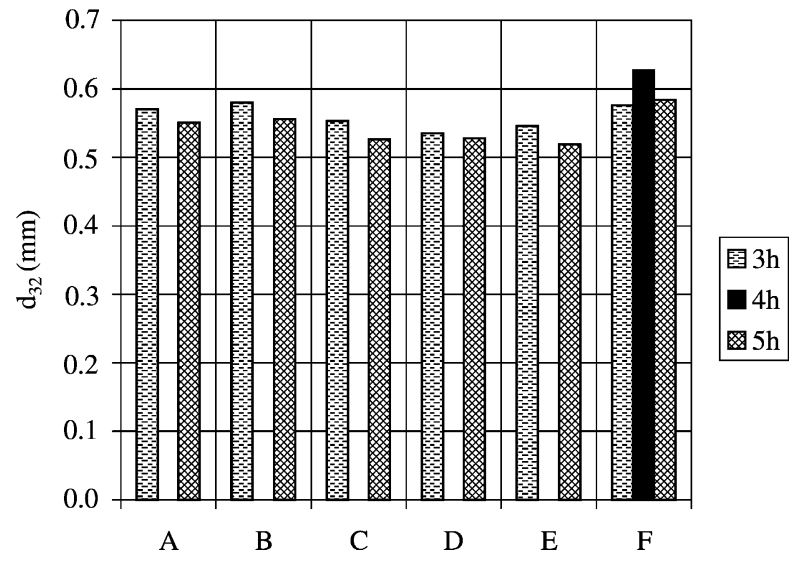

Fig. 4. Sauter-mean diameter obtained from 13 independent replicates under the same operating conditions $(N=113 \mathrm{rpm}, \phi=1.85 \%$ and $\theta=167 \mathrm{~s})$.

In Fig. 4, the Sauter-mean diameter is shown for each run (A-F) and for each time delay (3-5 h). A small difference in the Sauter-mean diameters is observed for the two extreme time delays, suggesting a slightly smaller average diameter at the longest time delay, which would be the case if steady state were not reached at the lowest residence time. However, in run $\mathrm{F}$, this trend is not observed, and the $4 \mathrm{~h}$ frame series strongly suggests that such differences may be entirely random. The effective attainment of stabilization may thus be taken as a fact. The small oscillations of the average diameters may be assigned to random fluctuations in external, uncontrolled, conditions (such as temperature drift inside the vessel, as a result of the energy dissipation-which translates into viscosity and interfacial tension variationand agitation speed variation-as predicted by the equipment documentation), as well as to residual random drop counting and measuring operator errors.

Cumulative drop volume distributions were computed from the measured diameters in each frame series and the corresponding confidence limits for each size class were calculated from Student's $t$-distribution at the $95 \%$ confidence level and $n=13-2=11$ degrees of freedom (13 being the number of available frame series, and 2 the number of degrees of freedom used by the computation of the average and standard deviation of the distribution).

The results are presented in Fig. 5, where the cumulated distribution plots for the 13 replicates (frame series) are seen to entirely fall within the $95 \%$ probability confidence channel of the typical values. Measurements by the new method are thus proved reliable.

Fig. 6 shows the ratio of the standard deviation to the average drop contents of each cell over the 13 replicates of the total drop volume in each size class. Plot A refers to the cumulative distribution (i.e., to cumulated classes) and plot $\mathrm{B}$ refers to the histogram (i.e., to disjoint individual classes).

From the comparison of the two plots, the conclusion is obvious that the use of the cumulated distribution diminishes the relative measurement error for the largest size

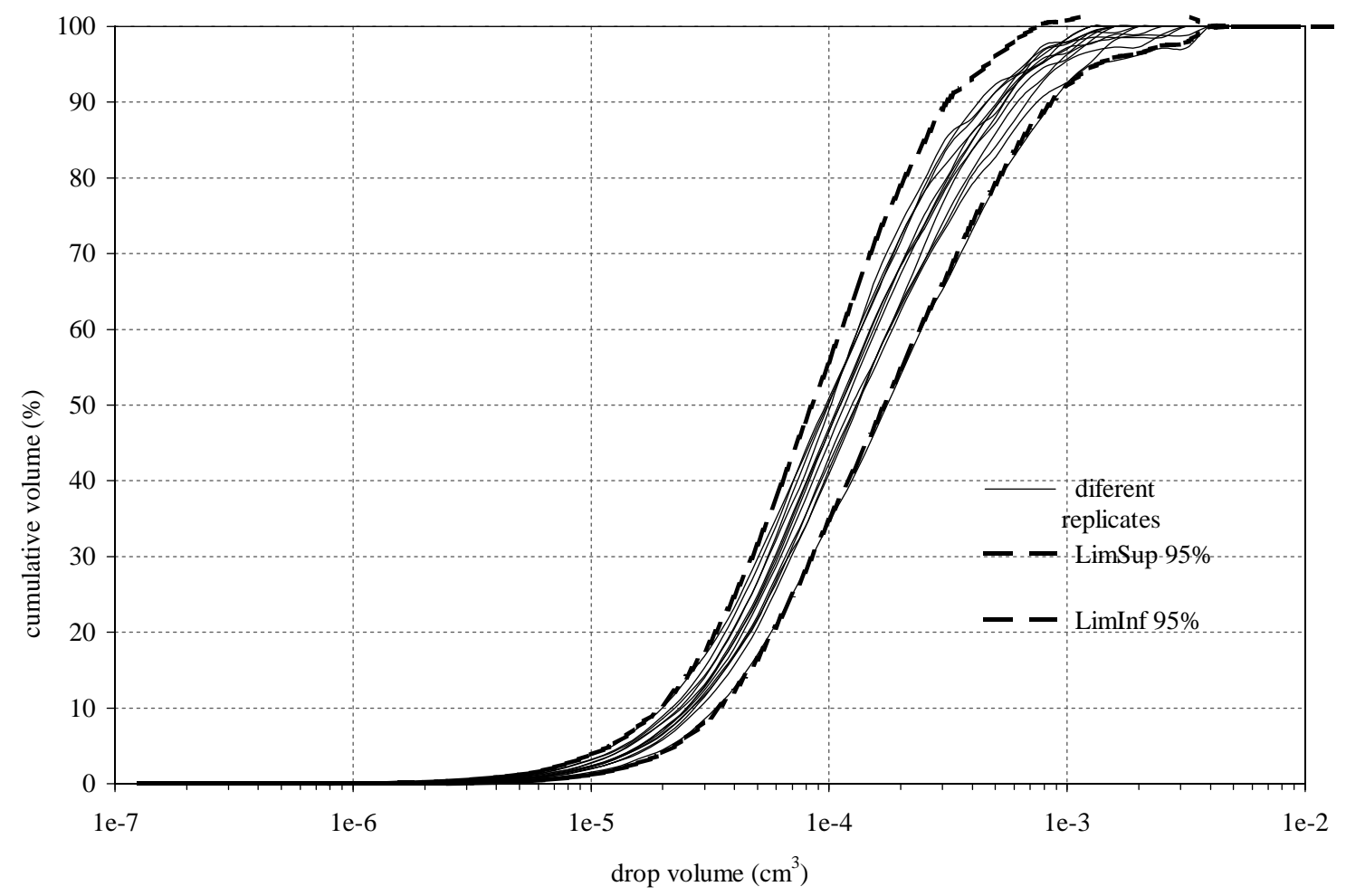

Fig. 5. Cumulative volume distributions obtained from 13 independent replicates under the same operating conditions $(N=113$ rpm, $\phi=1.85 \%$ and $\theta=167 \mathrm{~s})$. 


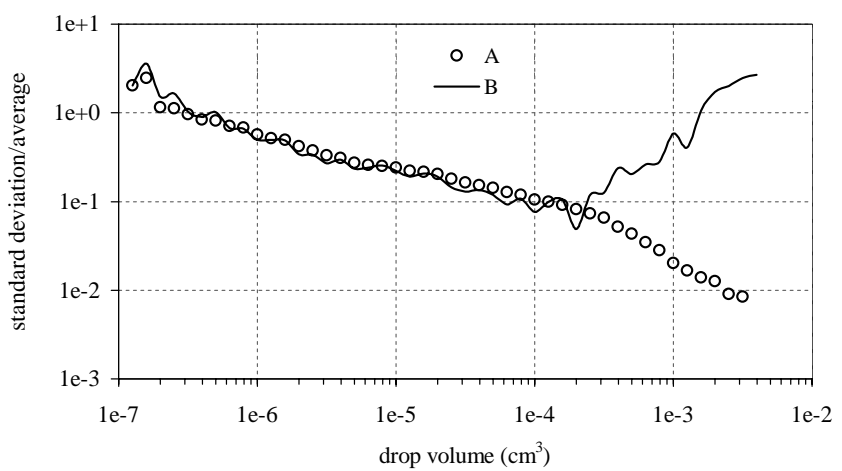

Fig. 6. Ratio of the standard deviation to the average over the 13 replicates of the total drop volume in each size class (plot A refers to the cumulative distributions and plot $\mathrm{B}$ refers to the histogram).

classes, where the number of drops may become statistically non-representative while their volume weighs inordinately in the distribution. In fact, the analysis of plot B in Fig. 6 shows larger relative errors for both (larger and smaller) end classes due to the small number of drops effectively counted in these classes. This happens for two different reasons: for the larger drops, because they are actually infrequent; for the smaller drops, because they are often hidden by the larger ones.

\section{Results and discussion}

\subsection{Steady-state continuous flow system}

As expected from the influence of the drop feed stream, relatively wide drop-size distributions are obtained (see continuous operation plot in Fig. 7), showing the irregularities imparted by the larger feed drops.

\subsubsection{Influence of the mean residence time}

An increase in the average residence time within the vessel is, of course, obtained by means of a decrease of the

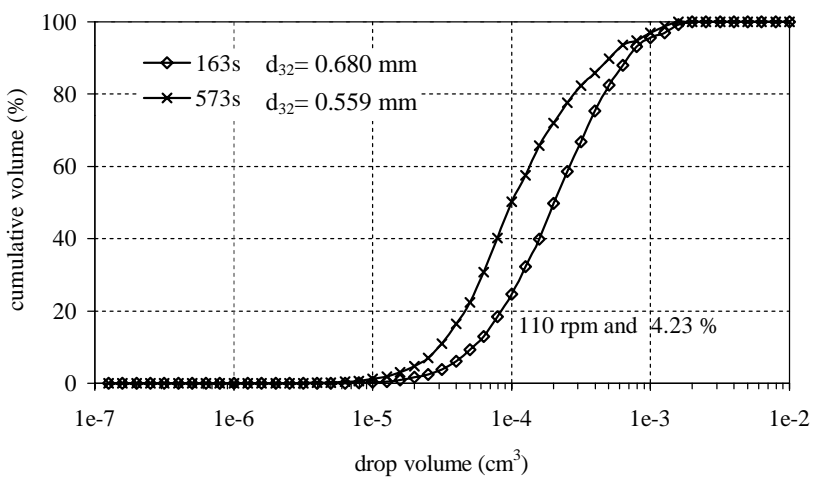

Fig. 8. Cumulative volume distributions for the runs with $N=110 \mathrm{rpm}$ and $\phi_{\text {average }}=4.23 \%$ for different dispersed phase hold-ups, at the steady state of a continuous flow system.

total feed flow-rate, and this situation means that the vessel contents is less influenced by the (coarse) feed drop-size distribution, and correspondingly more by the longer time available for drop breakage.

In Fig. 8, the influence of the mean residence time on the drop-size distribution within the vessel is shown for an agitation speed of $110 \mathrm{rpm}$ and hold-up of $4.23 \%$. The figure shows that an increase in the average residence time correlates with a decrease in the average drop size within the vessel; this is due to the average feed drop size being larger than the average size at equilibrium. This effect is particularly obvious in the cumulative size distribution for $573 \mathrm{~s}$, which is displaced to the left of the one for $163 \mathrm{~s}$; it is also apparent in the average $\left(d_{32}\right)$ drop diameter, which is significantly higher for the $163 \mathrm{~s}$ distribution. These results are thus compatible with theoretical expectations.

\subsubsection{Influence of the agitation speed}

Figs. 9 and 10 show the influence of the agitation intensity on the drop-size distribution for different residence times and dispersed phase hold-ups.

The above drop-size distribution plots clearly show that an increase of the agitation speed leads to finer sized drop

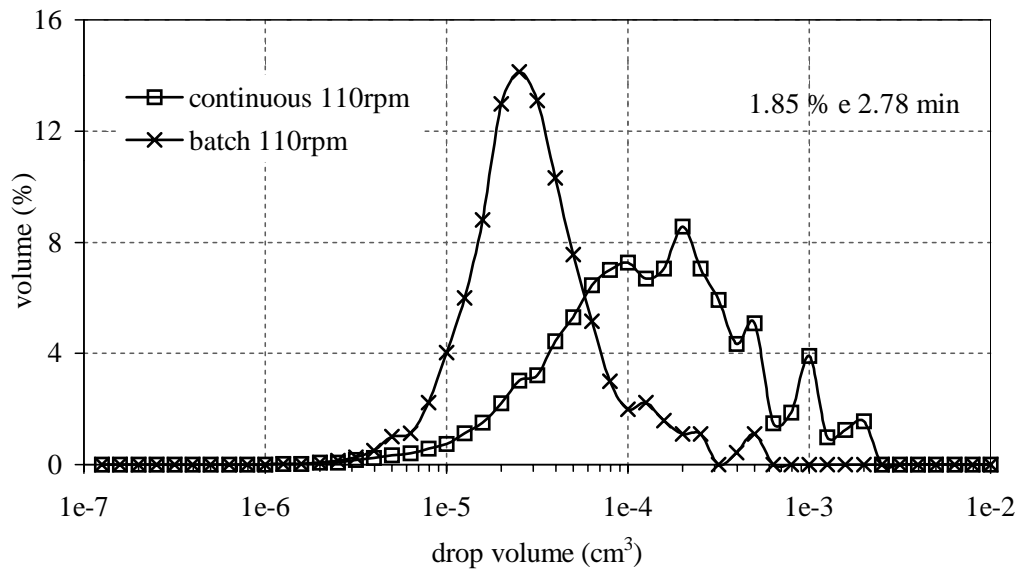

Fig. 7. Volume distributions for the runs with $\phi=1.85 \%$ and $N=113 \mathrm{rpm}$-batch and continuous flow $(\theta=167 \mathrm{~s})$ systems. 


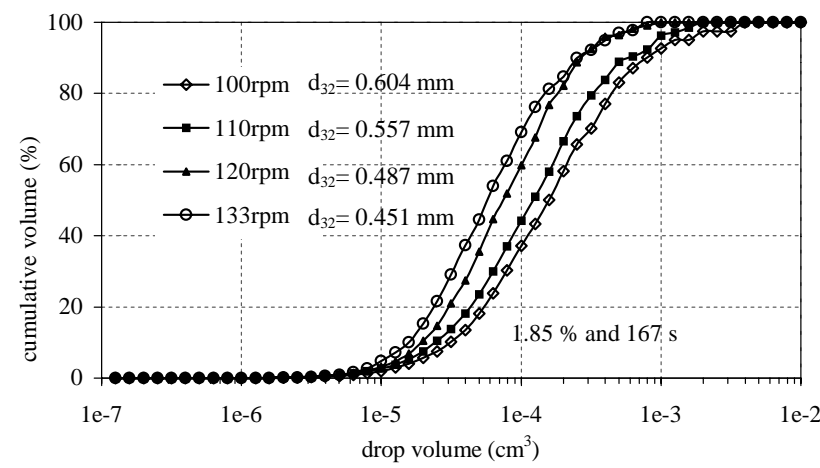

Fig. 9. Cumulative volume distributions for the runs with $\phi=1.85 \%$ and $\theta=167 \mathrm{~s}$, for different agitation speeds, at the steady state of a continuous flow system.

distributions, which is confirmed by the $d_{32}$ values. Thus, the agitation power increases drop breakage frequency (shown by the decrease of the average drop size with increased agitation) and decreases drop size dispersion (shown by slightly higher slopes of the median zone of the cumulated distribution plot for higher agitation rates).

\subsubsection{Influence of the dispersed phase hold-up fraction}

Fig. 11 shows the influence of the dispersed phase hold-up fraction (controlled by the dispersed to continuous phase flow ratio) on the drop-size distribution and average drop size.

The plots clearly show that, even in such lean dispersions, higher hold-ups lead to larger drops, which highlights, contrary to many expectations and hasty assumptions, the relevance of inter-drop coalescence in determining the behaviour of liquid-liquid dispersions. Accordingly, for these same runs, the average $\left(d_{32}\right)$ diameter also increases with hold-up.

Since the dispersed phase hold-up measures the volume fraction of the dispersed phase in the total dispersion volume, the higher is this fraction, the higher is the collision frequency between drops. It is this increased collision fre-

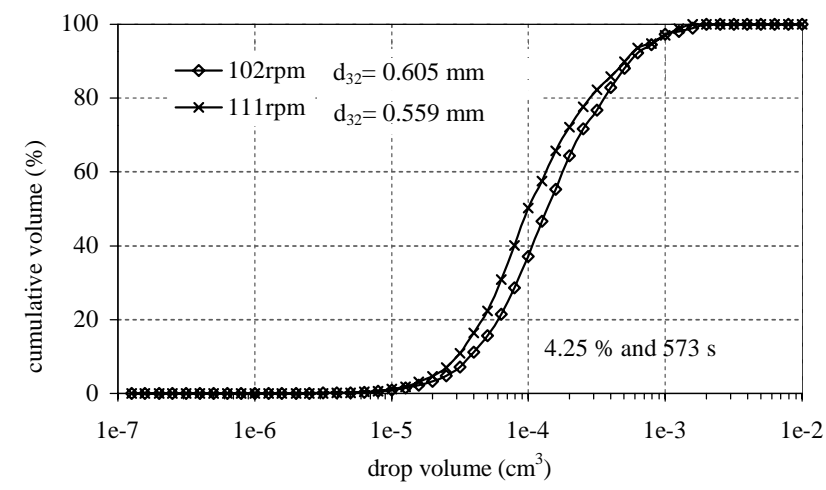

Fig. 10. Cumulative volume distributions for the runs with $\phi=4.25 \%$ and $\theta=573 \mathrm{~s}$, for different agitation speeds, at the steady state of a continuous flow system.

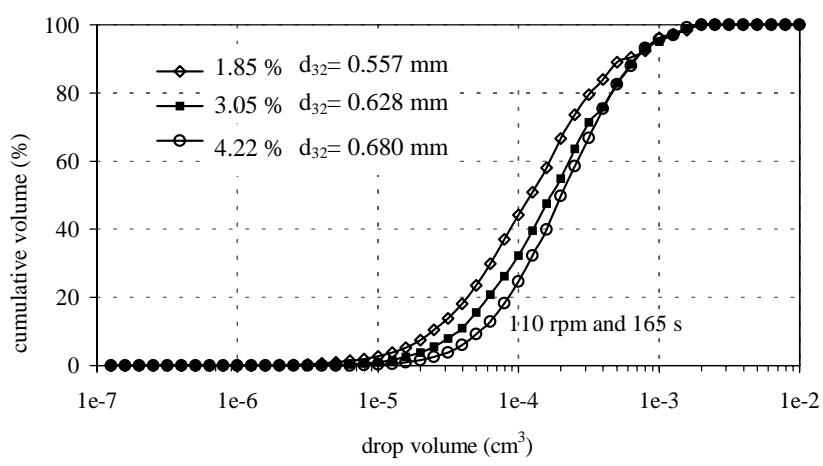

Fig. 11. Cumulative volume distributions for the runs with $N=110 \mathrm{rpm}$ and $\theta_{\text {average }}=165 \mathrm{~s}$ for different dispersed phase hold-ups, at the steady state of a continuous flow system.

quency that promotes drop coalescence and, thus, increases drop sizes. This is particularly evident in the larger displacement to the right of the lower segment of the cumulative curve, which testifies for an increasing disappearance of the smaller drops.

These findings are entirely consistent with, and quantitatively interpreted in, recent theoretical work on agitated dispersions in both mixer [30] and column [19] equipment.

\subsection{Steady-state batch system}

Contrasting with the continuous flow system, otherwise identical operating conditions for the batch system yield much narrower drop-size distributions, which is also much more sensitive to the agitation intensity (Figs. 7 and 12, where the batch operation plots contrast strongly with the continuous operation ones). This is the result of the lack of a feed stream in the closed (batch) system, the operating variables that influence the hydrodynamics within the vessel and the resulting drop-size distribution being limited to the agitation speed and the dispersed phase hold-up.

The plot in Fig. 12 compares the cumulated drop-size distributions for the batch and the continuous systems under

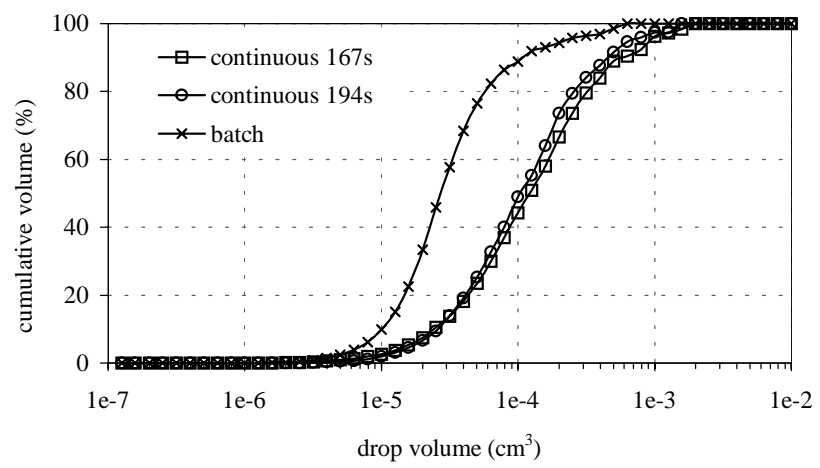

Fig. 12. Cumulative size distributions for the batch system and for two residence times of the continuous system (steady state, $\phi_{\text {average }}=2.1 \%$ and $N_{\text {average }}=112 \mathrm{rpm}$ ). 
Table 3

Operating conditions for the experiments comparing the batch and continuous flow systems

\begin{tabular}{llll}
\hline Flow & $\begin{array}{l}\text { Residence } \\
\text { time }(\mathrm{s})\end{array}$ & $\begin{array}{l}\text { Agitation } \\
\text { speed }(\mathrm{rpm})\end{array}$ & $\begin{array}{l}\text { Hold-up } \\
(\%)\end{array}$ \\
\hline Continuous & 167 & 110 & 1.85 \\
Continuous & 194 & 114 & 2.16 \\
Batch & - & 111 & 2.17 \\
\hline
\end{tabular}

two different average residence times. Due to experimental difficulties, it was not possible to compare experiments with exactly the same hold-ups and agitation speeds. Relevant operating conditions are given in Table 3 .

Thus, the experiments to be compared have hold-ups differing by no more than $8.8 \%$ ( $0.18 \%$ units) of a nominal value of $2.1 \%$, and agitation speeds differing by no more than $1.9 \%$ (2.2 rpm) of a nominal value of $112 \mathrm{rpm}$.

As far as the two continuous experiments are concerned, the effects of the variations in speed and hold-up are apt to compensate each other, so that the cumulative curves are closer together than desired. On the other hand, difficulties in the flow control of the pumps and in the acquisition of optimized images have prevented us from using as large a difference in residence times as we would wish (their values being 167 and $194 \mathrm{~s}$ ). Thus, although the difference between the two measured drop-size distribution plots is small, so that they are, probably, within each other's confidence channels, they live up to theoretical expectation. In the asymptotic limit of infinite residence time for the continuous system, the drop-size distribution is equal to the one for the batch system. As a matter of fact, in this case, the drop sizes within the vessel become independent of the feed drop size because, for infinitely long residence times, the fraction of the feed that escapes the interaction effects (surely predominant, but not exclusive, breakage in this case) becomes negligible.

The planned improvements in the lighting system will hopefully significantly extend the range of accessible operating conditions, to fully characterize the dispersions' hydrodynamic behaviour.

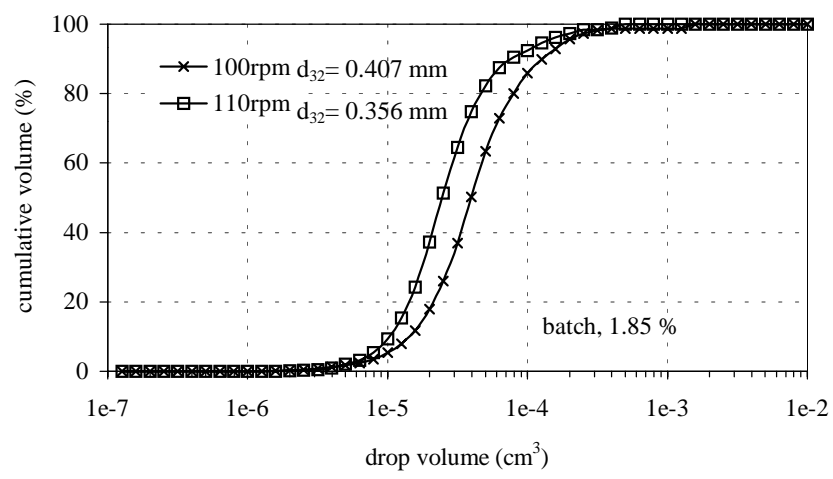

Fig. 13. Cumulative size distributions for the runs with $\phi=1.85 \%$ for two agitation speeds, batch system, stationary state.

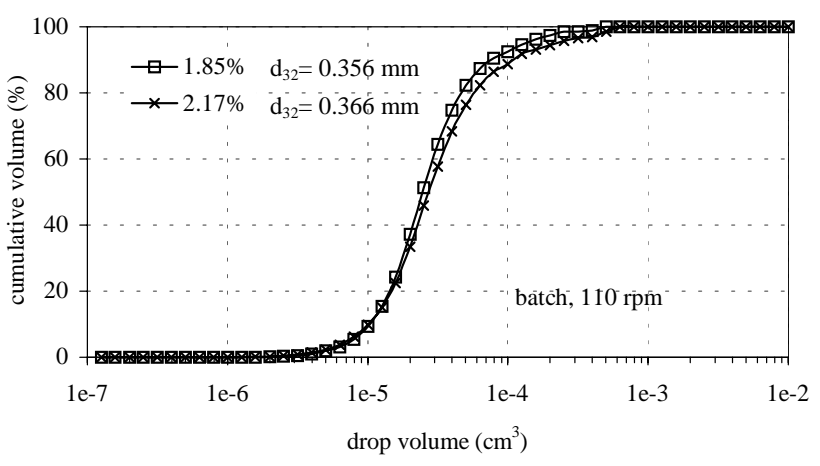

Fig. 14. Cumulative volume distributions for the runs with $N=110 \mathrm{rpm}$ for two dispersed phase hold-ups, batch system at steady state.

Table 4

Sauter-mean diameter for the runs with $N=100 \mathrm{rpm}$ for two dispersed phase hold-ups

\begin{tabular}{lll}
\hline Agitation speed (rpm) & Dispersed phase hold-up (\%) & $d_{32}(\mathrm{~mm})$ \\
\hline 100 & 1.85 & 0.408 \\
100 & 2.17 & 0.452
\end{tabular}

\subsubsection{Influence of the agitation speed}

Fig. 13 demonstrates the influence of even small changes in the agitation speed on the drop-size distribution.

It is clear that, as expected, higher agitation speeds lead to greater drop accumulations in the smaller size classes, the cumulative curve for $110 \mathrm{rpm}$ being displaced to the left relative to the one for $100 \mathrm{rpm}$. Analysis of the $d_{32}$ values confirms that higher agitation speeds lead to a decrease in average drop size.

\subsubsection{Influence of the dispersed phase hold-up fraction}

Fig. 14 demonstrates the influence of the dispersed phase hold-up on drop-size distribution and average drop size.

The plot shows that, even in batch mixers, where drop breakage develops to full extent (while in continuous flow it is held back by short residence time), an increase in hold-up from 1.85 to $2.17 \%$ brings about a measurable increase of the drop-size distribution towards the larger sizes, again as a result of non-negligible increased coalescence. In terms of average drop size, the effect is still more evident for lower agitation speeds (as shown in Table 4), where higher coalescence rates are expected.

\section{Conclusions}

1. An experimental batch/continuous agitated vessel and non-invasive dispersed phase imaging system (immune to disturbing effects on the hydrodynamics of the dispersion and to corrosion of optical devices) was set-up, tested and used in the study of interacting drop swarms.

2. The present equipment and procedures have been shown to be adequate and sufficiently accurate to reveal 
and quantitatively characterize the main features of the hydrodynamic behaviour of liquid-liquid systems, including the demonstration of the significantly important, often neglected, inter-drop coalescence processes, even in the leanest dispersions (hold-ups lower than 5\%).

3. Although, so far, limited to lean dispersions, the already available instrumental system and data treatment procedure yield accurate and physically meaningful drop-size distribution data, which are essential in detailed quantitative, experimental and theoretical, studies of the interacting (breakage and coalescence) behaviour of drop swarms, in liquid-liquid reaction and mass transfer processes.

4. The lighting system and the basic data handling and drop identification and measurement algorithm procedures tested easily lend themselves to the implementation of promising ongoing improvements, which will hopefully extend their usefulness to the study of much higher hold-ups.

\section{Acknowledgements}

This work was carried out under the gratefully acknowledged financial supports of the European Community Fund FEDER (through the project PRAXIS/P/EQU/13190/1998, endorsed by the Portuguese Foundation for Science and Technology, FCT), of the IPP-Fundo de Apoio à Investigação, project P/11/98 and of the CIEA-ISEP.

\section{References}

[1] D.K. Chang-Kakoti, W.-Y. Fei, J.C. Godfrey, M.J. Slater, Drop sizes and distributions in rotating disc contactors used for liquid-liquid extraction, J. Separ. Process. Technol. 6 (1985) 40.

[2] D. Magioris, A. Goulas, A.H. Alexopoulos, E.G. Chatzi, C. Kiparissides, Use of CFD in prediction of particle size in suspension polymer reactors, Comp. Chem. Eng. 22 (1998) S315.

[3] A.H. Alexopoulos, D. Magioris, C. Kiparissides, CFD analysis of turbulence non-homogeneity in mixing vessels. A two-compartment model, Chem. Eng. Sci. 57 (2002) 1735.

[4] V. Alopaeus, J. Koskinen, K.I. Keskinen, Simulation of the population balances for liquid-liquid systems in a nonideal stirred tank. Part 1. Description and qualitative validation of the model, Chem. Eng. Sci. 54 (1999) 5887.

[5] R.B. Olney, Droplet characteristics in a countercurrent contactor, AIChE J. 10 (6) (1964) 827.

[6] W.J. Korchinsky, S. Azimzadeh-Khatayloo, An improved stagewise model of countercurrent flow liquid-liquid contactors, Chem. Eng. Sci. 31 (1976) 871.

[7] W.J. Korchinsky, J.J.C. Cruz-Pinto, Experimental confirmation of the influence of drop size distributions on liquid-liquid extraction column performance, Chem. Eng. Sci. 35 (1980) 2213.

[8] V. Rod, T. Misek, Stochastic modelling of dispersion formation in agitated liquid-liquid systems, Trans. IChemE 60 (1982) 48.
[9] M.M.L. Guimarães, J.J.C. Cruz Pinto, Mass transfer and dispersed phase mixing in liquid-liquid systems I, Comp. Chem. Eng. 12 (11) (1988) 1075 .

[10] M.M.L. Guimarães, P.F.R. Regueiras, J.J.C. Cruz Pinto, Mass transfer and dispersed phase mixing in liquid-liquid systems II, Comp. Chem. Eng. 14 (2) (1990) 139.

[11] L.M. Ribeiro, P.F.R. Regueiras, M.M.L. Guimarães, C.M.N. Madureira, J.J.C. Cruz Pinto, The dynamic behaviour of liquid-liquid agitated dispersions. I. The hydrodynamics, Comp. Chem. Eng. 19 (3) (1995) 333.

[12] L.M. Ribeiro, P.F.R. Regueiras, M.M.L. Guimarães, C.M.N. Madureira, J.J.C. Cruz Pinto, The dynamic behaviour of liquid-liquid agitated dispersions. II. Coupled hydrodynamics and mass transfer, Comp. Chem. Eng. 21 (5) (1997) 543.

[13] L.M. Ribeiro, P.F.R. Regueiras, M.M.L. Guimarães, J.J.C. Cruz Pinto, Efficient algorithms for the dynamic simulation of agitated liquid-liquid contactors, Adv. Eng. Software 31 (2000) 985.

[14] J.H. Bae, L.L. Tavlarides, Laser capillary spectrophotometry for dropsize concentration measurements, AIChE J. 35 (7) (1989) 1073.

[15] J.C. Godfrey, Mixers, in: J.C. Godfrey, M.J. Slater (Eds.), LiquidLiquid Extraction Equipment, Wiley, Chichester, 1994.

[16] R.W. Williams, M.S. Beck, Process Tomography Principles, Techniques and Applications, Butterworths, Oxford, 1995.

[17] G.T. Bolton, W.J. Korchinsky, R.C. Waterfall, Imaging immiscible liquid-liquid systems by capacitance tomography, Trans. IChemE A 77 (1999) 699.

[18] A.W. Pacek, I.P.T. Moore, A.W. Niewnow, R.V. Calabrese, Video technique for measuring dynamics of liquid-liquid dispersion during phase inversion, AIChE J. 40 (12) (1994) 1940.

[19] M.L. Gomes, Comportamento Hidrodinâmico de Colunas Agitadas de Extracção Líquido-Líquido, Ph.D. Thesis, Universidade do Minho, Braga, Portugal, 1999.

[20] A.W. Pacek, A.W. Niewnow, Measurements of drop size distribution in concentrated liquid-liquid dispersions: video and capillary techniques, Trans. IChemE A 73 (1995) 512.

[21] R.V. Calabrese, A.W. Pacek, A.W. Nienow, Coalescence of viscous drops in stirred dispersions, in: The 1993 IChemE Research Event, University of Birmingham, 1993, p. 642.

[22] T. Misek, European Federation of Chemical Engineering, Recommended Systems for Liquid Extraction Studies, The Institute of Chemical Engineers, 1978.

[23] J.H. Rushton, E.W. Costich, H.J. Everett, Power characteristics of mixing impellers-Part I, Chem. Eng. Prog. 46 (8) (1950) 395.

[24] J.H. Rushton, E.W. Costich, H.J. Everett, Power characteristics of mixing impellers-Part II, Chem. Eng. Prog. 46 (9) (1950) 467.

[25] W. Buljalski, A.W. Nienow, S. Chatwin, M. Cooke, Dependency on scale of power number of Rusthon disc turbines, Chem. Eng. Sci. 42 (2) (1987) 317.

[26] C.M. Stoots, R.V. Calabrese, Mean velocity field relative to a Rusthon turbine blade, AIChE J. 41 (1) (1995) 1.

[27] A.C. Johansson, J.C. Godfrey, Dispersed phase distribution in liquidliquid mixing in an agitated tank, IChemE Symposium Series No. 140, 1996, p. 253.

[28] M.M.M. Ribeiro, M.M.L. Guimarães, P. Teixeira, J.M. Soeiro, C.M.N. Madureira, J.J.C. Cruz Pinto, Estado Estacionário e Dinâmico de Dispersões Líquido-Líquido em Misturadores-Decantadores, PRAXIS XXI/EQU/13190/1998 Project Report, 2001.

[29] P.M. Bapat, Mass transfer in liquid-liquid continuous flow stirred tank reactor, Ph.D. Thesis, Illinois Institute of Technology, Chicago, IL, 1982.

[30] M.M.M. Ribeiro, Medição e Interpretação do Comportamento Hidrodinâmico de Dispersões Líquido-Líquido em Vaso Agitado em Regime Contínuo e Descontínuo, Ph.D. Thesis, Universidade de Aveiro, Aveiro, Portugal, 2002. 